\title{
6 claves para el buen funcionamiento de proyectos de mediación en centros educativos
}

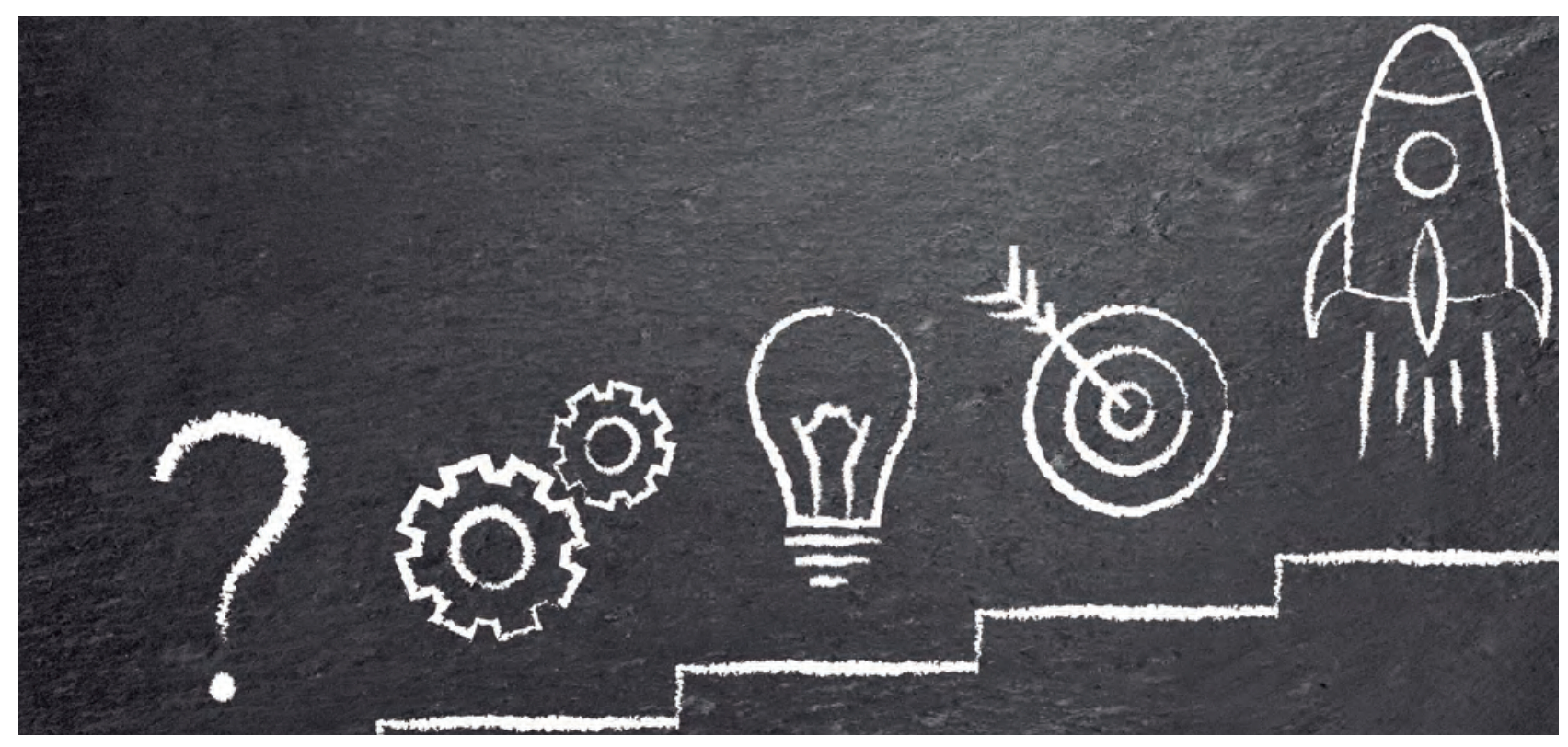

\section{Una perspectiva desde la empresa}

La gran mayoría de proyectos educativos caen en los mismos errores. Los proyectos de mediación intentan ponerse en marcha sin los conocimientos logísticos básicos como para lograr la eficacia y sostenibilidad del proyecto. Pon Solución asesora a decenas de centros educativos para la creación de equipos de mediación, interviniendo a su vez en conflictos educativos, familiares y empresariales. 6 claves para revisar el proyecto que se está aplicando en el centro. 6 claves para adelantarse a los acontecimientos. 


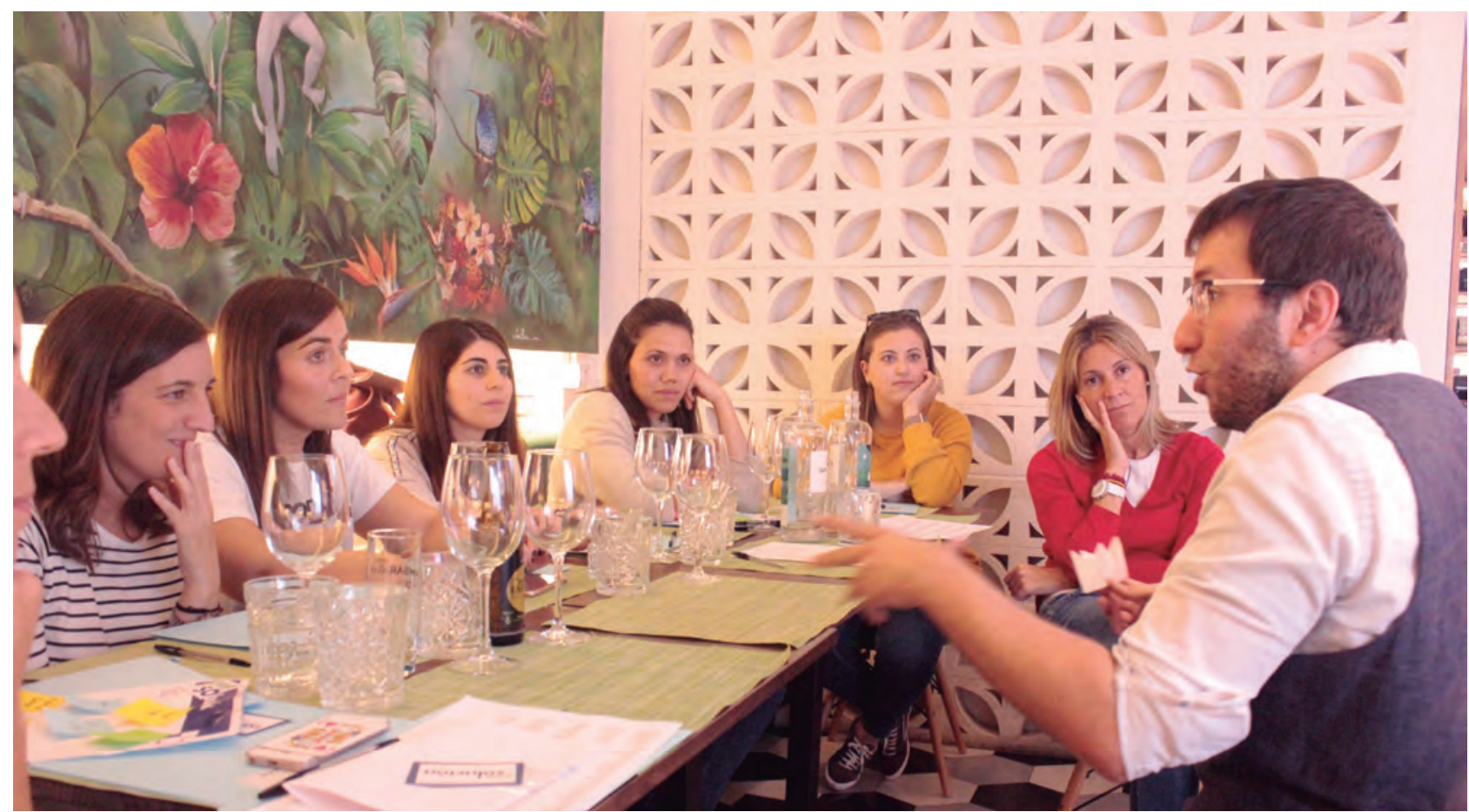

Iniciar cualquier proyecto es complicado y sin ayuda lo es más todavía. Dar los primeros pasos, sin referentes a los que seguir, hace que la inseguridad acompañe a la intuición y, poco a poco, vamos dando forma a algo que el mundo piensa que es imposible, que el esfuerzo no merece la pena y la caída es inminente.

Bajo esta premisa nace Pon Solución. Una empresa privada dedicada a la mejora de la convivencia en el ámbito familiar, escolar y empresarial, con la mediación transformativa como norte en nuestros proyectos. Para ello, se puede dar pescado o enseñar a pescar, nosotros hacemos ambos. Generamos cambios en hijos adolescentes que se van alejando del núcleo familiar, despertamos la esperanza en parejas que sienten que no se entienden, ayudamos a resolver problemas en las escuelas que desbordan a cualquiera o recuperamos los ambientes de diálogo dentro de las empresas para garantizar el buen clima entre empleados. Si el problema ya es presente, esta es tu opción, pide ayuda antes de que se haga más tarde. Si es latente, aún puedes aprender a pescar y, a la larga, con creces, merece la pena. Nos dedicamos a la formación de personas en gestión de grupos; para aprender desde cómo resolver conflictos, propios y ajenos, hasta cómo fomentar el compañerismo o el diálogo pacífico. A su vez, y con garantías abrumadoras de

\section{Ayudamos a resolver \\ problemas en las escuelas \\ que desbordan a cualquiera o recuperamos los ambientes de diálogo dentro de las empresas para garantizar el buen clima}

éxito, ayudamos a los centros educativos a la creación de proyectos de mediación, donde el alumnado mediador es el que resuelve los problemas que surgen entre sus compañeros.

Tras ayudar a más de 40 centros en año y medio, mientras nos esforzábamos en mantener a flote nuestra empresa, hemos podido extraer una serie de conclusiones y estamos seguros de que su difusión podría ayudar tanto a los centros educativos que quieran iniciar sus proyectos, como a la revisión de aquellos que ya lo estén haciendo. Así como a aquellas personas que quieran vivir de la mediación, porque se han dado cuenta de que a través de ella el cambio en ti mismo y en la gente que te rodea es posible.

\section{No nadar a contracorriente}

Para empezar, debemos tener la aprobación de la directiva y una vez la tene- 
mos, es altamente recomendable sensibilizar al resto del claustro. No solo para conseguir un equipo de personas dispuestas a implicarse, sino también para que, si no quieren colaborar, por lo menos que no impidan el avance del proyecto. A estas personas no se les vence, se les conquista.

Ahora bien, nuestro mayor consejo es que no hay que rendirse ante la adversidad. Cuanto más difícil sea el contexto de aplicación, más estrategia será necesaria. A menudo, uno no es profeta en su tierra y hace falta ayuda externa para conquistar y sensibilizar tanto a la directiva como al resto de compañeros.

\section{Obsesión por la sostenibilidad}

El mayor aprendizaje que hemos adquirido del asesoramiento es la necesidad constante de tener el concepto de sostenibilidad presente. De entrada, saber diferenciar y aplicar los conceptos de eficacia y eficiencia. No basta con llegar al objetivo, hay que hacer un aprovechamiento verdaderamente eficiente de los recursos disponibles ya que en el contexto educativo son realmente escasos. Las personas, su energía y motivación, los recursos económicos y, sobre todo, el tiempo suelen ser factores limitantes que condicionan el desarrollo de la iniciativa.

\section{Regeneración constante de alumnado}

Cuántos más mediadores, mejor. Es importante que nuestro primer objetivo sea tener alumnado mediador en todas las aulas, de tal manera que pase lo que pase siempre habrá alguien formado y sensibilizado para detectar el problema e iniciar el protocolo.

Teniendo en cuenta que la educación es cíclica, que hay alumnos que entran y salen del centro y del proyecto, es necesario formar anualmente al alumnado, tanto a los que no han recibido formación, como a los que ya tienen una pequeña base. El estado emocional y madurativo de un joven cambia de año en año, por lo que cuando vuelva a vivirlo

\section{ÁQORA DE DROFESORES}

¿Cuánto profesorado hay implicado en el proyecto?

¿Qué funciones ejerce cada uno?

¿Hay un coordinador del proyecto? Si este se fuera ¿continuaría funcionando?

¿Cuántos mediadores hay en el centro?

¿Hay mediadores en todas las aulas?

¿Cada cuánto se forma?

¿De cuántas horas es el curso? ¿Qué contenidos imparte?

¿Es atractivo para el alumnado?

¿El profesorado que lo imparte se lo cree y lo disfruta?

¿Se hacen mediaciones en el centro educativo? Si la respuesta es no, ¿por qué?

¿Se hacen suficientes para que todo el equipo mediador se sienta útil?

¿Qué otras funciones tiene el equipo mediador aparte de hacer mediaciones?

¿Qué fama tiene el equipo de mediación?

¿Qué saben las familias sobre la mediación?

¿Qué hace el centro para difundir la mediación?

¿Qué hace el centro para reconocer la labor del alumnado mediador?

¿Cómo me imagino el proyecto de mediación de aquí dos años?

Si no tienes respuesta para alguna de estas preguntas 0 ves que la respuesta no es acorde a los consejos del artículo, ya tienes un camino por donde avanzar.

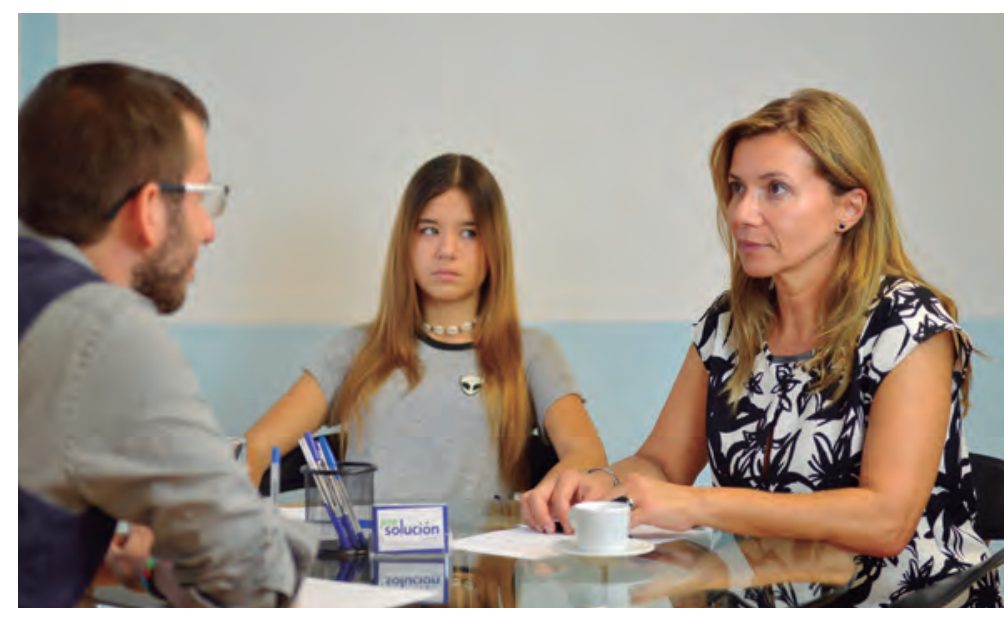

seguro que lo percibe con matices diferentes. Sin tener en cuenta que el curso de mediación escolar es de entre 10 y 20 horas, mientras que una persona mediadora profesional debe recibir como mínimo un curso de 200 horas de formación, por lo que el reciclaje anual no solo es recomendable sino necesario.

De hecho, desde Pon Solución proponemos un cambio de paradigma, donde "ser mediador" no es "hacer mediaciones" sino participar en el curso de mediación. No solo recibiendo formación sino ayudando a los nuevos en su formación. El curso de mediación lo reciben los alumnos desde $2^{\circ}$ de la ESO y son mediadores desde $3^{\circ}$. 


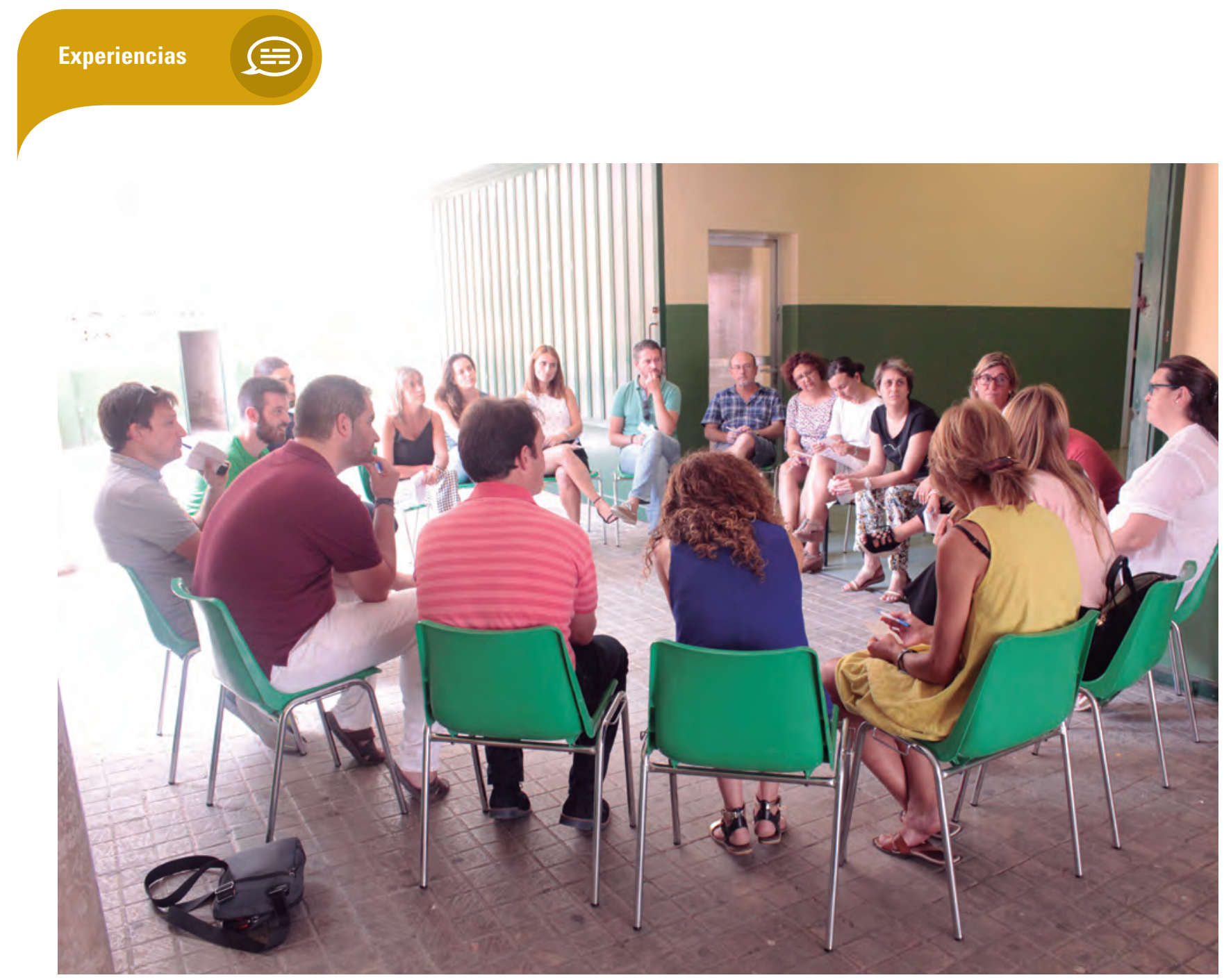

\section{¿Qué hacemos con el alumnado de $1^{\circ}$ de la ESO?}

Cada vez empiezan los proyectos de mediación antes, muchos colegios de primaria ya tienen alumnos mediadores en $5^{\circ}$ y $6^{\circ}$. Imaginemos que este alumnado llega al instituto y allí no pueden participar en el proyecto de mediación hasta $2^{\circ} \circ 3^{\circ}$. Esto genera un sentimiento de frustración que probablemente haga que perdamos la motivación del alumnado por contribuir al desarrollo de la convivencia en los cursos donde más recursos necesitamos.

Así que, para atender a esta demanda, se forman como premediadores, encargados de ayudar a los mediadores a detectar los conflictos, de hacer una atención temprana y de derivar los conflictos para su gestión eficiente. De esta manera, todos son protagonistas y todos tienen como referente a una persona mayor.

\section{El efecto Pandora}

Todo proyecto tiene su evolución cuando se pone en marcha, tras hacer la publicidad motivadora del servicio, sucede lo que hemos denominado el efecto
Pandora. De repente, en un centro que parecía no tener conflictos, aparece una alta demanda de mediaciones. Ya que el conflicto no era explícito, estaba latente, y al crear los canales de ayuda y transmitir la confianza suficiente, las personas los utilizan.

Al poco tiempo, la demanda va bajando hasta que prácticamente deja de haber mediaciones y entonces, ¿qué hacemos con un gran grupo de alumnado formado y motivado? Por un lado, al cambiar el eje a la formación no perciben tanto la reducción de la demanda del servicio, pero por otro hay que crear otro tipo de iniciativas con las que darles funciones y así mantener alta su motivación, implicación y repercusión. Un centro con un gran número de mediadores y mediadoras bien formados, motivados y orgullosos de serlo es garantía de una alta calidad de convivencia en el centro educativo.

\section{Marketing en la escuela}

Si algo nos ha enseñado la empresa privada es la importancia de la imagen que tiene el resto de la comunidad del producto que ofrecemos. En este tipo de 


\section{Nuestro proyecto nació de un}

\author{
sueño, de una utopía donde la \\ mediación fuera lo habitual y \\ no la locura de unos pocos
}

iniciativas que trabajan temas tan delicados, se debe trabajar la imagen que se tiene de ellos para evitar frases como "la mediación es para centros conflictivos", "la mediación hace que el profesorado pierda la autoridad", "Ios de mediación son los raritos del centro", etc.

Todo esto se puede evitar invirtiendo en iniciativas que acerquen la mediación a la comunidad. Cuando Ilevamos mucho tiempo trabajando en el mismo sector nos volvemos endogámicos pensando que todo el mundo comparte nuestra visión de la realidad. Nada más lejos, sino aproximamos nosotros la mediación a estas personas, su desconocimiento hará que siembre la duda sobre los objetivos y utilidad de la iniciativa.

En conclusión, para que todo proyecto pueda empezar a funcionar la organización es clave. Saber qué debemos hacer, quién se va a encargar, cómo podemos automatizar procesos, cómo delegar responsabilidades, establecer prioridades, qué es importante y qué es urgente, qué problemas van a surgir y cómo los pode-

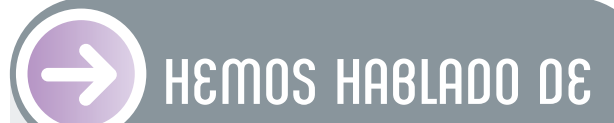 \\ Mediación educativa; proyecto de centro; asesoramiento externo; motivación; sostenibilidad.}

Este artículo fue solicitado por PADRES Y MAESTROS en septiembre de 2017, revisado y aceptado en diciembre de 2017. mos prevenir o afrontar. Tener toda esta información permite, no solo andar sobre seguro en el proceso que queremos emprender, sino también disfrutar de lo que hacemos, ya que este tipo de iniciativas deben ser gratificantes.

Lo más interesante es que si cambiamos los términos educativos y hablamos de empresa o familia, el sistema funciona igual. Organización, sostenibilidad, previsión, expectativa y motivación son valores que, adecuados a cada contexto, fomentan el buen desarrollo del bienestar de las personas que lo forman. Por ese motivo no dejamos de intervenir en decenas de familias, centros educativos y empresas. Porque creemos en el empoderamiento del individuo, enseñándole a pescar, para que así cada vez seamos más los que fomentemos los valores que acompañan a la mediación.

Nuestro proyecto nació de un sueño, de una utopía donde la mediación fuera lo habitual y no la locura de unos pocos. Hoy en día, no es una utopía es un ideal alcanzable que ya forma parte de la realidad de muchas personas. Si no hubiéramos sido capaz de imaginarlo, no habríamos sido capaces de lograrlo. Como dijo una alumna nuestra: "Tus locuras son nuestras oportunidades, gracias por hacernos formar parte de ellas". Te invito a que hagas de las tuyas la realidad de muchas personas •

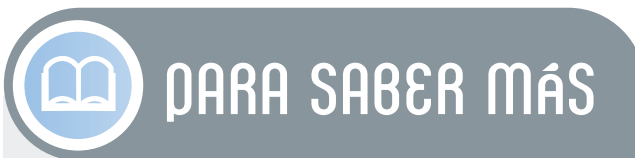 \\ Boqué, C. (2005). Tiempo de mediación. Bar- celona: Grupo planeta. \\ HARO, M. D. (2011). Soy mediador, soy media- dora. Un programa de formación en reso- lución pacífica de conflictos y mediación escolar: tercer ciclo de Educación Prima- ria. Autoedición. \\ Torrego, J. C. (2000). Mediación de conflic- tos en instituciones educativas. Madrid: Narcea.}

